\title{
MARKETING DE EXPERIÊNCIA: ESTRATÉGIAS PARA IMPULSIONAR O MARKET SHARE E FORTALECER A MARCA DO ENERGÉTICO ENERGY
}

\author{
EXPERIENTIAL MARKETING: STRATEGIES \\ TO INCREASE THE MARKET SHARE \\ AND STRENGTHEN ENERGY'S BRAND
}

Data de submissão: 22-03-2016 Aceite: 07-07-2016

Camila Portella de Azambuja ${ }^{1}$ Roberto Schoproni Bichueti²

\section{RESUMO}

O mercado competitivo tem influenciado o comportamento dos consumidores, de modo que estratégias para fortalecer o relacionamento com o cliente e aumentar a visibilidade das marcas têm se tornado foco das empresas. Nesse contexto, não é mais suficiente a marca ser vista: ela precisa ser sentida. Portanto, as estratégias antes utilizadas devem ser adaptadas ou alteradas em sua totalidade, a fim de envolver os consumidores em ações e experiências inesquecíveis, que proporcionem lembranças positivas de valor sobre as marcas. Tendo em vista que a empresa responsável pela comercialização da bebida energética Energy está enfrentando dificuldades em fortalecer sua marca e estar próxima de seu público-alvo, neste estudo, buscou-se conhecer a percepção de uma amostra do público-alvo do energético, com o intuito se identificar quais estratégias de marketing de experiência poderiam figurar como uma possível solução para sanar as deficiências encontradas. Os resultados indicam que conceder experiências únicas, entretenimento e ludicidade ao público do Energy é uma alternativa que tende a aproximar o público da marca e aumentar gradativamente seu market share.

Palavras-chave: Marketing de Experiência. Comportamento. Marca. Valor.

\footnotetext{
1 Possui graduação em Administração pela Universidade Federal de Santa Maria, UFSM. Santa Maria. Rio Grande do Sul. Brasil. E-mail: camilaportellaaz@gmail.com

2 Possui graduação em Administração pela Universidade Federal de Santa Maria, UFSM, mestrado em Administração pela Universidade Federal de Santa Maria, UFSM e doutorado em Administração pela Universidade Federal de Santa Maria, UFSM. Santa Maria. Rio Grande do Sul. Brasil. E-mail: robertobichueti@hotmail.com
} 


\begin{abstract}
The competitive market has influenced the consumer behavior. Strategies to build up customer relationships and increase the visibility of brands, has become a companies' focus. We know that is not enough the brand be seen, it must be felt. Strategies before used must be adapted or changed in its entirety; therefore, the solution is to involve consumers in stocks and unforgettable experiences that provide value and brand's positive memories. In view of that the company responsible for marketing the energy drink Energy is struggling to build up their brand and be close to your target audience, in this study, we sought to understand the perception of a sample of the energy target audience, with order to identify which experience marketing strategies might include as a possible solution to remedy the deficiencies found. Grant unique experiences, entertainment and playfulness to the Energy's public, is an alternative that tends to bring the public to the brand and, gradually, increase your market share.
\end{abstract}

Keywords: Experiential Marketing. Behavior. Brand. Value.

\title{
1 INTRODUÇÃO
}

Os avanços tecnológicos na transmissão de informações e os mercados sem barreiras provocaram mudanças no comportamento dos consumidores. A partir do momento em que o cliente se identifica com os valores e o posicionamento de uma empresa, a probabilidade de que este se fidelize a organização aumenta.

Em tempos em que o relacionamento personalizado e individual com o cliente está sendo cada vez mais valorizado e estimulado, surge um novo conceito: o marketing de experiência. Nesse contexto, a gestão da experiência do cliente acompanha o marketing de relacionamento, gerando valor para os clientes e consistindo em um conjunto de interações, que, aliadas às vendas, transformam-se em experiências poderosas e em grandes retornos à empresa (SCHMITT, 2004).

A Empresa X, uma das empresas mais rentáveis e lucrativas do mundo e alvo deste estudo, tem a valorização de pessoal como uma das bases de sua gestão. A visão da organização de ser a maior empresa de bebidas tem norteado suas ações, tendo em vista que tudo é realizado levando em consideração o bem-estar dos colaboradores, dos donos dos pontos de venda e, principalmente, dos consumidores finais. Conhecer seu comportamento e seus interesses e saber qual bebida combina com cada um são ações que possibilitam que a empresa trace metas para ser a número um na mente do consumidor e perpetuar esse status.

Com um acompanhamento diário e semanal do volume de vendas, a empresa procura sempre desenvolver planos de ação para melhorias. Na linha de energéticos, encontra-se uma oportunidade de desenvolvimento: o energético Energy, que, comparado a seus concorrentes, possui um volume de vendas baixo, embora a visibilidade da marca esteja em expansão. No âmbito da região sul do Brasil, especificamente nos estados do Rio Grande do Sul e de Santa Catarina, o Energy tem cumprido sua meta - fazer com que o produto esteja presente no maior número de pontos de venda possível, com pelo menos uma caixa, garantindo, assim, certa "cobertura de mercado". O Energy é direcionado para quem vive intensamente na balada, no esporte ou na carreira, motivo pelo qual presentear o público-alvo do Energy com experiências únicas e inesquecíveis consiste em uma alternativa que tende a aproximar o público da marca.

Portanto, este estudo busca conhecer a percepção dos consumidores do energético Energy e, a partir dos resultados, propor um planejamento de ações de marketing para aumentar a visibilidade da marca. Surge, assim, o problema que norteia o presente estudo: qual é a percepção dos consumidores sobre o Energy e quais são as alternativas para fortalecer a marca e impulsionar seu market share? 
Nesse sentido, o objetivo deste estudo é planejar ações para fortalecer a marca e impulsionar o market share do Energy, utilizando estratégias de marketing de experiência. Especificamente, pretende-se levantar dados sobre a marca Energy; analisar a percepção de consumidores atuais e potenciais do Energy; realizar a análise dos principais concorrentes do energético Energy; e propor à Empresa $\mathrm{X}$ um planejamento de ação de marketing de experiência.

\section{REFERENCIAL TEÓRICO}

\subsection{Marketing}

Segundo a American Marketing Association (AMA) (2013), o marketing pode ser definido como um conjunto de processos que cria, comunica, entrega e troca ofertas de valor para os clientes, os parceiros e a sociedade em geral. Nesse sentido, o marketing vai além da propaganda e da venda: o ponto central de suas estratégias é a entrega de valor.

O composto de marketing, ou mix de marketing, é um conjunto de variáveis que a empresa deve controlar de forma a ter um planejamento de marketing eficiente, aumentando a probabilidade de obter a resposta desejada vinda do mercado. Os quatro P's que formam o mix de marketing são: produto, preço, praça e promoção (SANTINI; LUDOVICO, 2013).

No presente trabalho, o foco consiste na promoção. Segundo Kotler (1998), a promoção destina-se à comunicação dos atributos do produto que persuadem os clientes a adquiri-lo. Uma excelente promoção pode garantir o sucesso de uma empresa, podendo ser realizada por meio de venda pessoal, propaganda, promoção de vendas e eventos.

As marcas que hoje produzem entretenimento, enquanto objetivo de marketing, estão conseguindo fazer uma gestão mercadológica melhor, porque elas estão dando entretenimento e ludicidade aos seus consumidores. Rabelo (2015) afirma que as organizações devem levar em conta, além do lucro, o fato de que as pessoas querem consumir valores; assim quanto mais valor a marca produzir, mais amada, respeitada e duradoura será.

Nesse contexto, ganha destaque o market share, uma expressão que, segundo o Guia do Marketing (2013), significa a quota de mercado ou participação de mercado de uma empresa em algum segmento. É possível, assim, atingir o mercado de duas formas: crescimento vertical, que é a disputa diária com a concorrência nos Pontos de Venda (PDV) onde a empresa atua; e crescimento horizontal, que é a disputa por meio da expansão de mercados, geograficamente ou não (VANUCCI, 2009).

A expansão horizontal vem ganhando evidência nos últimos anos, pois as organizações estão investindo na promoção, aumentando seus investimentos em comunicação e buscando os consumidores em potencial (VANUCCl, 2009). Essa estratégia consolida a relação "organizaçãoconsumidor" por meio do fortalecimento da marca, o que acaba dificultando a entrada da concorrência na região de atuação (VANUCCl, 2009).

Toda empresa ou empreendedor deve, assim, analisar sua concorrência, a fim de discernir os pontos fortes e fracos, os atributos e os diferenciais. Segundo Bizzotto (2008, p. 74), a Matriz de Avaliação de Valor (MAV) permite identificar o que as empresas já estabelecidas valorizam em termos de atributos do produto. Para montar a MAV, é preciso colocar, no eixo horizontal, os atributos atuais nos quais as empresas já estabelecidas investem e, no eixo vertical, indicar por meio de uma escala (que varia de baixo a alto) o nível de oferta de cada atributo sob o ponto de vista do cliente. Quanto maior for a pontuação, maior é o investimento que a empresa faz nesse atributo.

Para reconstruir elementos de valor, surge o modelo das quatro ações. Segundo Kim e Mauborgne (2005), a primeira ação, eliminar, força a empresa a considerar uma possível eliminação de atributos que há muito tempo percebe como certos, mas que, infelizmente, não devem 
ser utilizados por não trazerem mais o retorno esperado ou até mesmo por destruírem valor. A segunda ação, reduzir, incentiva a empresa a examinar atributos em que há investimentos em demasia, ocasionados pelo esforço desesperado de superar os concorrentes - continuar com um comportamento assim eleva os custos e causa estagnação no retorno do investimento. Já a terceira ação, elevar, leva a empresa a verificar e corrigir quais são os aspectos que o setor como um todo mais utiliza. A quarta e última ação, criar, ajuda a organização a descobrir estratégias de valor que nunca utilizou antes, mas que trazem um retorno maior. Após avaliar e realizar essas quatro ações, a empresa poderá criar uma nova curva de valor que ilustra os aspectos de maior valor para ela e para seus consumidores (KIM; MAUBORGNE, 2005).

\subsection{Marca}

A marca, segundo Rabelo (2015), é uma entidade sensorial e imaginária. É sensorial pois pode ser percebida pelos nossos sentidos, possuindo gosto, forma, volume e cor; e é imaginária pois povoa a nossa mente com valores que não necessariamente são sentidos pelo nosso campo sensorial. As marcas precisam, assim, apresentar algo a mais aos seus clientes. Segundo Kotler (2005 apud LINDSTROM, 2005), elas precisam ser capazes de transmitir e entregar uma experiência sensorial e emocional:

Não basta anunciar visualmente um produto ou um serviço. Vale a pena acrescentar algum som, que pode ser uma música, palavras ou símbolos poderosos. A combinação de estímulos visuais e auditivos causa um impacto de $2+2=5$. Vale ainda mais a pena provocar outros canais sensoriais - sabor, tato, olfato - para aumentar o impacto total.

Estudos recentes confirmam que os consumidores estão tão bombardeados por informações e anúncios que não basta mais a empresa ser vista: ela precisa ser sentida. Com tantos concorrentes diretos e indiretos, as empresas correm o risco de não serem lembradas. Segundo Luís (2014), a chave consiste, dessa forma, em envolver os consumidores em uma ação inesquecível e positiva, utilizando todos os sentidos do ser humano como ferramentas.

\subsection{Marketing de experiência}

O marketing de experiência ou marketing sensorial é uma estratégia de marketing que visa criar um vínculo de exclusividade para fortalecer o relacionamento da empresa com o seu consumidor, incentivando-o a participar de experiências com as marcas de produtos ou serviços (LUís, 2014). Nesse sentido, não basta apenas ver; conforme o marketing de experiência, é preciso sentir, escutar ou experimentar. A ideia é criar vínculos emocionais entre o consumidor e a marca, utilizando elementos como cores e luzes, por exemplo, para promover estímulo visual (MELLO apud CAMPOS, 2010).

Ao participar de experiências, o consumidor deixa de ser apenas um receptor de informações, para fazer parte da marca com a qual ele se identifica. A ligação que ocorre quando um consumidor se identifica com os valores fundamentais da marca pode ser de longa duração, se for reforçada ao longo do tempo (RABELO, 2015). Segundo o Market Design (2015), por meio de novas experiências, as pessoas são naturalmente conduzidas a novas conexões mentais, sendo possível perceber com um novo olhar as situações. Segundo Silva e Tincani (2013, p. 150),

O Marketing de Experiências pode ser utilizado para alavancar uma marca em declínio, diferenciar um produto dos concorrentes, criar identificação para uma empresa, promover inovações ao consumidor ou colaborador e induzir o consumo de certo produto ou marca com fidelidade, proporcionando assim benefícios para a marca. 
A gestão da experiência do cliente, segundo Schmitt (2004), pode ser implementada em cinco etapas, que são moldadas pelo gestor. Na primeira etapa, é preciso conhecer o contexto sociocultural em que o cliente está inserido, já que isso permite ter os primeiros insights do que será possível realizar. Na segunda etapa, deve-se encontrar o posicionamento a ser utilizado, bem como o valor que o cliente pode esperar do produto ou serviço a ele fornecido. Em seguida, na terceira etapa, é o momento de projetar a experiência da marca. Já a quarta etapa, em que ocorre a estruturação da interface do cliente, vai garantir a continuidade da experiência, pois trata de todos os pontos de contato que o cliente poderá ter com a empresa. A quinta e última etapa diz respeito ao princípio da continuidade - os clientes valorizam uma empresa dinâmica, que se adapta às suas necessidades e traz sempre alguma melhoria ou algo novo.

Diante disso, Rocha (2013) salienta que o marketing de experiência não é realizado para gerar vendas imediatas. $O$ objetivo de suas estratégias é construir um relacionamento com o cliente, despertando desejos de uma interação e necessidades que ele mesmo não sabia que possuía.

\section{MÉTODO}

No presente trabalho, optou-se por utilizar a pesquisa qualitativa como uma das formas de coleta de dados. Segundo Malhotra (2005, p. 114), "a pesquisa qualitativa proporciona melhor visão e compreensão do problema", sendo baseada em amostras pequenas e não representativas, em que os dados não são analisados estatisticamente, mas por meio da transcrição da percepção dos respondentes.

Entre as abordagens diretas mais utilizadas, não disfarçadas, estão a discussão em grupo e a entrevista de profundidade. Morgan (1997, p. 16) define os grupos focais como "uma técnica de pesquisa que coleta dados por meio das interações grupais ao se discutir um tópico especial sugerido pelo pesquisador". Segundo Veiga e Gondim (2001), o grupo focal pode ser visto como uma possibilidade de compreender a construção das percepções, atitudes e representações sociais de grupos humanos acerca de um tema específico.

Para formar um grupo focal, o primeiro passo é modelar o ambiente: o local deve estar equipado com tudo o que for necessário para que a discussão em grupo seja confortável para os participantes e para que seja possível registrar seus sentimentos. Recrutar e selecionar os participantes também é uma etapa fundamental, em que se define o público-alvo da pesquisa. Ademais, o grupo deve ser composto de oito a 12 pessoas, no máximo, pois o excesso de pessoas reunidas em uma discussão pode comprometer o andamento do grupo focal e, consequentemente, a qualidade das respostas (MALHOTRA, 2005).

É preciso, ainda, haver um moderador, que exerce uma função importante e deve estar preparado para guiar o grupo focal. Sua postura não pode ser tendenciosa, uma vez que ele deve ser capaz de estabelecer uma harmonia no grupo, manter a discussão e questionar os participantes para extrair o máximo de percepções possíveis. 0 moderador deve ter um roteiro que o ajude a guiar a discussão e centrar-se nos principais objetivos. Além disso, um roteiro bem-elaborado garante confiabilidade e organização à pesquisa (MALHOTRA, 2005).

Neste estudo, optou-se, assim, pela realização de três grupos focais com consumidores atuais e potenciais, pertencentes ao público-alvo do Energy: um grupo focal presencial e dois grupos on-line. Para a realização do grupo focal presencial, oito pessoas, de 18 a 27 anos, participaram do estudo, guiadas por um moderador com um roteiro previamente definido. $\mathrm{O}$ ambiente possuía luzes, música e alguns lanches para que os participantes se sentissem em uma pequena festa. Alguns vídeos foram selecionados para mostrar as propagandas do energético veiculadas 
nas mídias digitais, além de shows e eventos patrocinados pela marca. Durante 20 minutos, houve sampling, momento em que os participantes experimentaram o Energy, tiveram contato com a lata e a logomarca e puderam expressar suas opiniões sobre o energético. Todas as impressões e percepções foram registradas, e as etapas do grupo focal foram filmadas e gravadas, a fim de garantir que as informações a serem analisadas fossem precisas. Em seguida, foram realizados dois grupos focais on-line com seis participantes cada, em uma rede social virtual, com data e hora marcada e um roteiro semelhante ao utilizado no grupo presencial.

Para manter o sigilo da empresa e dos produtos estudados, foram utilizadas as seguintes nomenclaturas: Empresa X, para a empresa estudada; Energy, para o produto estudado; Soft para um produto relacionado ao Energy; e Alfa, Beta, Gama, M, T, B e E! para os concorrentes diretos.

\section{RESULTADOS}

\subsection{Análise do perfil dos participantes}

A maioria dos participantes está na faixa de 21 a 23 anos (40\%) e na faixa entre 18 e 20 anos (30\%). Outros $25 \%$ dos participantes têm entre 24 e 26 anos, e apenas 5\% têm de 27 a 29 anos. O Energy possui um público-alvo jovem que frequenta baladas e eventos e que busca energia para curtir até o final da noite. Logo, a amostra de participantes possuía a faixa etária de 18 a 29 anos.

Todos os participantes são estudantes de nível superior. Geralmente, as áreas de estudo e atuação das pessoas refletem a sua personalidade e o seu comportamento. Na área das ciências sociais e humanas, estão $55 \%$ dos participantes, que pertencem aos cursos de Publicidade e propaganda, Administração, Design e Direito. Já os cursos de Engenharia de produção, Engenharia civil, Arquitetura e Sistemas de informação abarcam 30\% dos participantes, enquanto que outros $20 \%$ pertencem à área da saúde, cursando Enfermagem e Radiologia. Foi possível perceber o quanto os participantes da área da saúde levantaram a questão de o energético ser um estimulante agressivo ao corpo humano, motivo pelo qual não consumam mais o produto, tendo optado por bebidas mais saudáveis e naturais. Notou-se, ainda, que os estudantes da área de ciências sociais e humanas, assim como os de exatas, possuem um comportamento semelhante. Os aspectos levantados por estes dizem respeito, em sua maioria, à credibilidade da marca, à visibilidade, à interação com o público e, principalmente, ao custo-benefício do produto.

\subsection{Energy}

O primeiro energético da Empresa X, Energy, foi lançado em 2011. Composto de guaranina, cafeína natural do guaraná e taurina, um aminoácido encontrado naturalmente no corpo humano e em alguns alimentos, o produto é feito para aquelas pessoas que vivem intensamente na balada, no esporte e na carreira. Como o principal foco da organização é a venda de latas em casas noturnas, a Empresa $X$ triplicou o investimento em promoção de festas e eventos. Devido a isso, além de ser vender em bares, casas noturnas e supermercados, a marca tem investido no patrocínio de grandes eventos, tais como o Tomorrowland e o Rock in Rio.

Nos primeiros meses de 2015, o Energy apresentou um comportamento lento de expansão, com pouca representatividade de market share. Porém, em maio e no início de junho, a produto vem apresentando um crescimento bastante significativo junto com o restante do segmento de Soft drinks (refrigerante, energético, isotônico e chá) da Empresa X. 


\subsection{Grupo focal presencial}

No decorrer do grupo focal presencial, percebeu-se que os participantes não são consumidores frequentes de energético: uma participante não consome; outra participante consome mais de três vezes por mês; e os demais participantes consomem esporadicamente, seja em baladas e durante os estudos e/ou a prática de esportes. Quando questionados sobre quais marcas vem à mente quando pensam em energéticos, as marcas citadas foram: Alfa, Beta, Gama e M. Os participantes citaram o Alfa por alegar que a empresa trabalha muito bem a marca, divulgando-a em múltiplos meios de mídia. Outros alegam que compram o energético que tem no supermercado, dando preferência àqueles que não possuem um preço muito elevado. Assim, geralmente compram o Beta em festas e o Alfa para tomar em casa com poucas pessoas - o preço dos energéticos em festa, segundo alguns respondentes, é mais caro que no supermercado, motivo pelo qual muitos não consomem o produto em festas ou eventos.

As campanhas publicitárias do Alfa foram citadas inúmeras vezes pelos participantes, que consideram essas interações da marca algo bom e que deve ser incentivado. O Energy foi citado poucas vezes, sendo lembrado pelos investimentos em tendas no interior de festas e por samplings.

Em seguida, foi transmitido um vídeo sobre a ação de um banco, utilizando um caixa eletrônico no Canadá. Nesse vídeo, o banco convidou alguns clientes para testar um novo caixa eletrônico: quando eles interagiam com o caixa, uma surpresa lhes é feita. Após visualizarem o vídeo, os participantes foram questionados sobre essas ações de experiência de marca e de interação com o público consumidor e com o público potencial. Todos alegaram que ações como essa são muito importantes e emocionantes, pois passam a sensação de preocupação por parte da marca em conhecer o cliente e, principalmente, fazer parte de sua vida. Em seguida, foram questionados se essas ações interfeririam em sua decisão de compra, ao que responderam que a decisão de compra é, muitas vezes, algo inconsciente.

Outros participantes disseram que o preço é um fator decisivo que está acima da experiência, mas que, no momento em que comparam dois produtos com o mesmo preço, a experiência atuará como um diferencial. Nesse contexto, as empresas precisam fazer o cliente perceber o valor agregado pelo qual está pagando. Um dos participantes, por exemplo, afirmou: "Você não pagaria oito reais em uma lata de Alfa se ela não tivesse um posicionamento de marca forte". Outros participantes entendem que as pessoas não compram energético como símbolo de ostentação, de modo que muitas preferem os mais baratos, tratando-o como uma bebida secundária, que serve para acompanhar alguma coisa, e não como item principal no consumo.

Após falarem sobre energéticos de forma geral, os participantes foram indagados sobre o seu conhecimento sobre o Energy. Disseram, então, que não conseguem associar o Energy com um energético, e sim com um guaraná, pelo grande e colorido símbolo que há em sua lata. Falta, assim, um posicionamento mais forte da marca em relação ao que é o Energy, que é visto pelos jovens como um energético para a balada e para as festas fechadas, interpretação que está alinhada ao posicionamento do produto.

Dos oito participantes, apenas um tinha experimentado o energético antes do grupo focal. Alguns nunca compraram por não possuir o hábito de consumir energéticos, enquanto que outros preferem marcas concorrentes. Há, ainda, aqueles que consideram o Energy caro, por realmente estar em um segmento premium. Acreditam que o Energy precisa desenvolver melhor a comunicação de marca e "aparecer" para o público-alvo. Por fim, demonstraram estar interessados em ver diversas marcas interagindo com o público em seu meio, pois gostariam de sentir as marcas mais próximas de seu dia a dia. 
Em uma das etapas do grupo focal presencial, destinada à experimentação $e$ ao contato com o produto, após experimentarem o Energy, os participantes afirmaram que seu sabor é leve, não sendo tão doce nem tão encorpado quanto o dos demais energéticos. Os participantes consideraram que a lata tem um tamanho bom para o consumo, porém visualizaram a logomarca como pouco expressiva - a presença do termo Soft na lateral da lata acaba atrapaIhando sua identidade. De maneira geral, o Energy foi aprovado pelos participantes, excedendo suas expectativas e fazendo com que se sentissem incentivados a buscar o produto nos estabelecimentos fornecedores.

\subsection{Grupo focal on-line}

Utilizando uma mídia social, foram realizados dois grupos focais on-line, cada um com seis pessoas. Nesse ambiente virtual, por alguns momentos, foi possível realizar perguntas, enviar vídeos sobre ações de experiência e ouvir a opinião de jovens de Porto Alegre, e de Santa Maria, duas cidades do Rio Grande do Sul, sobre o segmento dos energéticos. Os participantes foram guiados pelo moderador por um roteiro simples composto de sete perguntas.

Ao serem indagados sobre quais marcas vem à mente quando pensam em energéticos, citaram as seguintes marcas: Alfa, Beta e $M$. Devido às propagandas criativas, aos patrocínios e às intervenções da marca, Alfa é a mais lembrada. Dos 12 participantes, oito não são consumidores assíduos de energéticos, enquanto os outros quatro tomam o produto pelo menos uma vez por semana. Costumam consumir a bebida antes dos estudos, antes de ir ao trabalho e em festas. A maioria dos participantes considera as ações de marketing de experiência e as intervenções que muitas marcas realizam extremamente interessantes.

Quando questionados sobre a influência que as ações de marketing podem ter sobre decisão de compra, a maioria dos participantes afirmou que com certeza essas ações influenciam sua decisão. Nesse sentido, devido à música e ao ritmo da noite, provavelmente os respondentes não levariam em consideração as experiências, mas o preço ou a disponibilidade do produto na casa noturna, para decidir se comprariam ou não.

A maioria dos participantes afirmou, ainda, que não conhecia o Energy; e os poucos que conheciam disseram encontrar dificuldade em vê-lo nos pontos de venda. Acreditam que falta divulgação da marca, recordando superficialmente de quando lançaram o produto no Brasil, em meados de 2011.

\subsection{Análise dos concorrentes}

Os concorrentes diretos do energético listados são: Gama, Beta, E!, M, Alfa e T. Eles possuem um comportamento semelhante ao do energético em estudo: têm a energia como e acompanhamento do público-alvo em seu dia a dia, seja no esporte ou na balada, como foco. Basicamente, o Energy e seus concorrentes são compostos dos mesmos elementos: taurina e cafeína. Algumas marcas trazem também em sua composição certas vitaminas, como as do complexo $B$, e açúcares.

Todos os concorrentes diretos do Energy investem em patrocínios, principalmente de festas e eventos. Alguns concorrentes, como o Alfa, o M e o T, identificam-se com o público que pratica esportes, incluindo os radicais em motos e na neve, o Ultimate Fighting Championship (UFC) e a Fórmula 1 (F1). Além disso, percebeu-se que a faixa de preço dos concorrentes é semeIhante, variando de quatro a nove reais a lata. 
Com o grupo focal e outros pareceres, verificou-se que o energético não está entre as primeiras opções em termos de preferência de bebidas. Principalmente em baladas e eventos, os jovens preferem comprar cerveja ou vodca, em vez de comprar o energético. Uma das justificativas para esse comportamento, segundo os participantes do grupo focal, consiste no preço dos produtos: enquanto é possível encontrar cerveja por cinco reais na balada, uma lata de energético chega a custar 20 reais.

Como concorrentes substitutos do energético no setor de bebidas, foram listados: cervejas - Budweiser, Heineken, Skol Extreme e Stella Artois; vodcas e similares - Absolut, Skyy e Smirnoff; e whiskies - Jack Daniel's e Johnnie Walker. No Quadro 1, exposto a seguir, pode-se verificar os concorrentes substitutos, seu posicionamento e os patrocínios que realizam.

\begin{tabular}{|c|c|c|}
\hline \multicolumn{3}{|c|}{ Análise dos concorrentes substitutos } \\
\hline Marca & Posicionamento & Patrocínios \\
\hline \multicolumn{3}{|c|}{ Cerveja } \\
\hline Budweiser & $\begin{array}{l}\text { Inspirar os consumidores a serem livres, autênticos } \\
\text { e únicos. }\end{array}$ & $\begin{array}{l}\text { Fifa World Cup 2014, National } \\
\text { Football League (NFL) e UFC }\end{array}$ \\
\hline Heineken & $\begin{array}{l}\text { Ter experiências de vida e aspirações. Open your } \\
\text { world [Abra seu mundo]. }\end{array}$ & Champions League \\
\hline Skol Extreme & $\begin{array}{c}\text { Ser a cerveja oficial da noite. Perfeita para quem } \\
\text { começa o dia com o jantar e só termina com o café } \\
\text { da manhã. }\end{array}$ & $\begin{array}{l}\text { Skol Summer On, Carnaval e } \\
\text { festas }\end{array}$ \\
\hline Stella Artois & Ser a união de elegância e sofisticação. & $\begin{array}{l}\text { Torneio de Wimbledon, The } \\
\text { Open Championship e o Ken- } \\
\text { tucky Derby (Turfe) }\end{array}$ \\
\hline \multicolumn{3}{|c|}{ Vodca } \\
\hline Absolut & Ser o melhor da balada. & Festas e eventos \\
\hline Skyy & $\begin{array}{l}\text { Ser extremamente suave e versátil. Combina com } \\
\text { sua imaginação e com o que você quiser. }\end{array}$ & Festas e eventos \\
\hline Smirnoff & $\begin{array}{c}\text { Propor um brinde à vida real. Não importa qual } \\
\text { seja a ocasião, existe uma Smirnoff perfeita para } \\
\text { ela. }\end{array}$ & Festas e eventos \\
\hline \multicolumn{3}{|c|}{ Whisky } \\
\hline Jack Daniel's & $\begin{array}{l}\text { Celebrar o espírito independente e aqueles que } \\
\text { fazem as coisas à sua maneira e que se orgulham } \\
\text { de seu ofício. }\end{array}$ & Texas Rangers (Beisebol) \\
\hline Johnnie Walker & $\begin{array}{l}\text { Inspirar o progresso do ser humano. A uniformi- } \\
\text { dade e a qualidade de sabor é o que os mantêm } \\
\text { caminhando há quase } 200 \text { anos. }\end{array}$ & McLaren (F1) \\
\hline
\end{tabular}

Quadro 1 - Análise dos concorrentes substitutos

Fonte: elaborado pelos autores.

É possível perceber que muitas bebidas possuem o posicionamento de acompanhar a noite e de estar presente nas baladas, assim como o energético em estudo. Além disso, estão alocadas no segmento premium, tal como o Energy. Ressalta-se, ainda, que as cervejas citadas estão na mesma faixa de preço para o consumidor que o energético Energy: custam entre quatro e dez 
reais. Já o valor das vodcas e dos whiskies é mais elevado, por serem bebidas que apresentam um processo de fabricação mais elaborado, um teor alcoólico mais alto e um valor agregado elevado.

Os concorrentes substitutos do Energy em termos de suplementos e energy bars também foram analisados neste estudo devido à alta demanda que apresentam no mercado. As pessoas estão, cada vez mais, preocupadas com o bem-estar de seu corpo, com sua vitalidade e com sua estética, de modo que tanto as barras energéticas quanto os outros suplementos prometem melhoria no desempenho em esportes e nas demais atividades físicas. Esses concorrentes se diferem do Energy no que concerne ao posicionamento e ao público-alvo, como pode ser verificado no Quadro 2, a seguir.

\begin{tabular}{|c|c|c|}
\hline \multicolumn{3}{|c|}{ Análise dos concorrentes substitutos } \\
\hline Marca & Descrição & Patrocínios \\
\hline \multicolumn{3}{|c|}{ Energy bars } \\
\hline Clif Energy Bar & $\begin{array}{c}\text { É uma barra que contém ingredientes orgânicos } \\
\text { saudáveis, proporcionando nutrição e desempe- } \\
\text { nho e sendo construída para sustentar a sua aven- } \\
\text { tura. }\end{array}$ & Eventos esportivos. \\
\hline $\begin{array}{l}\text { Protein Bar Age } \\
\text { Outside }\end{array}$ & $\begin{array}{c}\text { É uma barra prática e saborosa que combina alta } \\
\text { concentração de proteínas de alto valor biológico } \\
\text { com } 22 \text { vitaminas e minerais. }\end{array}$ & UFC \\
\hline \multicolumn{3}{|c|}{ Suplementos } \\
\hline Black Burn & $\begin{array}{c}\text { É um suplemento à base de cafeína, projetado } \\
\text { para aumentar a resistência aeróbia durante os } \\
\text { exercícios de longa duração. }\end{array}$ & UFC \\
\hline $\begin{array}{l}\text { Therma Pro Hard- } \\
\text { core }\end{array}$ & $\begin{array}{l}\text { É um suplemento alimentar à base de extrato de } \\
\text { guaraná, que possui naturalmente altas concentra- } \\
\text { ções de cafeína. }\end{array}$ & UFC \\
\hline Waxy Maize & $\begin{array}{c}\text { É um suplemento energético para atletas, em pó, à } \\
\text { base de waxy maize (amido de milho ceroso), com } \\
20 \text { gramas de carboidratos por porção. }\end{array}$ & $\begin{array}{l}\text { Eventos de Fisiculturismo e } \\
\text { Arnold Classic Brasil }\end{array}$ \\
\hline
\end{tabular}

Quadro 2 - Análise dos concorrentes substitutos

Fonte: elaborado pelos autores.

Os suplementos, principalmente os produzidos pelas marcas Integralmedica, Nutrilatina e Neonutri, possuem um público relacionado a esportes como artes marciais e fisiculturismo. Os suplementos e as barras energéticas possuem um público em expansão que procura energia suficiente para desempenhar suas atividades diárias, ligadas a esportes ou não. Nesse sentido, quatro das marcas citadas patrocinam o UFC, ganhando, assim, grande visibilidade. Já a empresa da Waxy Maize patrocina muitos eventos de fisiculturismo, como o Arnold Classic Brasil. E a Clif Energy Bar, por sua vez, patrocina apenas eventos esportivos, desde escaladas a mountain bike.

Em relação ao preço, as barras energéticas e os suplementos são mais caras que o Energy; enquanto este é vendido por aproximadamente cinco reais, alguns dos suplementos custam entre 80 e 200 reais. Paralelamente, encontram-se as barras energéticas, que apresentam valor 
inferior ao do Energy: as barras energéticas estão sendo comercializadas na faixa de dois a cinco reais, podendo chegar a dez reais no caso das barras mais específicas e diferenciadas.

Salienta-se que o consumidor de Energy que busca um alimento para repor energia pode vir a enxergar as barras energéticas e os suplementos como opções com melhor custo-benefício. A maior variedade de produtos, influenciando na oferta e consequentemente no preço, torna os suplementos uma ameaça ao setor convencional de bebidas energéticas.

\subsubsection{Matriz de Avaliação de Valor}

Após coletar as percepções do grupo focal e analisar os concorrentes do Energy, foi desenvolvida a MAV do energético em estudo e de seus concorrentes, tendo sido escolhidos os concorrentes mais citados pelo público-alvo: Alfa, Beta, Gama e T. Os atributos do eixo horizontal foram selecionados mediante os dados do grupo focal e as demais informações adquiridas em outros meios. A seguir, encontra-se a MAV do presente estudo, exposta na Figura 1.

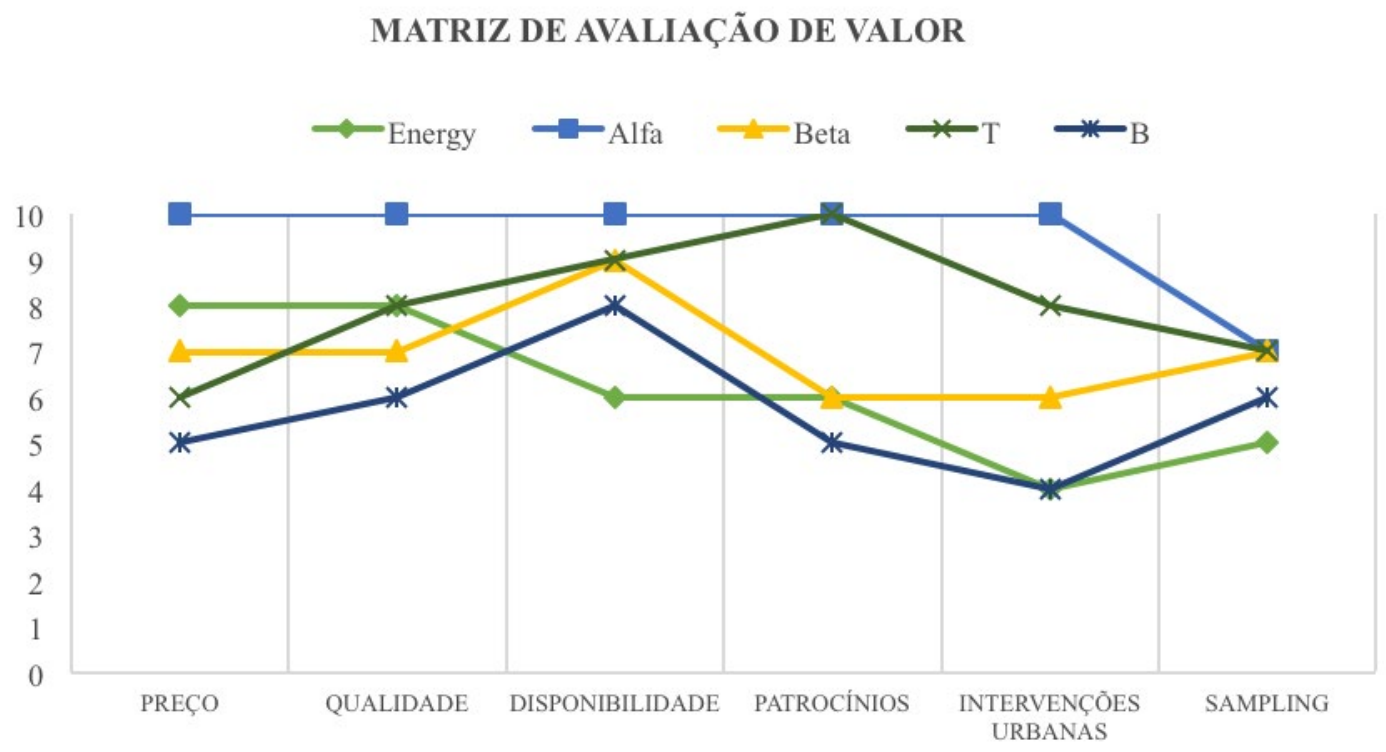

Figura 1 - Matriz de avaliação de valor.

Fonte: elaborada pelos autores.

Após a elaboração da MAV, pode-se perceber quais são os aspectos em que o Energy e seus concorrentes mais investem. A Alfa possui alto valor em cinco aspectos, possui o preço mais elevado dentre as concorrentes citadas, é percebida pelo público como a marca de maior qualidade e possui a maior cobertura de mercado. Além disso, verificou-se que a Alfa apresenta uma infinidade de campanhas publicitárias nas diversas mídias e investe em intervenções urbanas, nos centros das cidades e nos campi de universidades.

A concorrente T possui um preço um pouco inferior ao da Alfa, líder do mercado, com aspecto de qualidade igual ao do Energy, porém com disponibilidade maior nos pontos de venda. Quanto aos patrocínios, a T patrocina o UFC, competição que ampliou a visibilidade da marca; embora não invista muito em intervenções urbanas e em ações de sampling.

O energético Beta, por sua vez, possui um preço menor que o Energy e que o Alfa, apresentando qualidade mediana e disponibilidade alta nos pontos de venda. Em relação aos patrocí- 
nios, a marca Beta iguala-se ao Energy, mas investe mais em intervenções urbanas e em samplings.

Por fim, o energético $B$ apresenta menor preço e qualidade do que os outros energéticos da matriz, embora esteja mais disponível no mercado e invista mais em sampling do que o Energy. $O$ energético $B$ impulsionou suas vendas por investir em inúmeras ações de sampling, estratégia que proporcionou ótimos retornos à marca. Nos atributos patrocínios e intervenções urbanas, a $B$ ainda é uma marca em expansão, possuindo poucos investimentos notados pelo público-alvo.

\subsubsection{Modelo das quatro ações}

Após a elaboração da MAV, foi possível elencar algumas ações para suprir as demandas encontradas para o Energy. Por meio das observações dos participantes dos grupos focais, da análise informal do produto nos pontos de vendas e de conversas com os vendedores, foi possível construir um modelo das quatro ações. A seguir, no Quadro 3, são elencadas as quatro ações sugeridas para o Energy.

\begin{tabular}{|c|c|}
\hline Eliminar & Elevar \\
\hline Nenhum atributo. & $\begin{array}{c}\text { Visibilidade nas mídias, principalmente em canais de } \\
\text { música; } \\
\text { Presença em eventos e baladas do Rio Grande do Sul; } \\
\text { Disponibilidade do produto nos PDV; } \\
\text { Sampling; } \\
\text { Patrocínios de shows e eventos. }\end{array}$ \\
\hline Reduzir & $\begin{array}{c}\text { Criar } \\
\text { Vínculo com a bebida Soft. } \\
\text { Ações de marketing que aumentem a interação e apro- } \\
\text { ximem a marca do público; } \\
\text { Criar estratégias que incentivem o PDV a comprar Ener- } \\
g y ; \\
\text { Intervenços urbanas. }\end{array}$ \\
\hline
\end{tabular}

Fonte: elaborado pelos autores.

Não foram encontrados atributos a serem eliminados pelo Energy, havendo apenas um atributo a ser reduzido: vínculo com a bebida Soft. Mesmo todos sabendo que o Energy contém guaranina, a cafeína natural do guaraná, presente em sua composição, o Energy precisa se posicionar de maneira mais enfática como uma bebida energética. Infelizmente, muitos consumidores acreditam que o Energy é um refrigerante, pelo seu forte vínculo com o Soft.

Por meio da ação elevar, verificou-se que é necessário elevar a visibilidade da marca nas diversas mídias, como Facebook, YouTube, Twitter, televisão e canais pagos vinculados à música. O público-alvo do energético está sempre conectado à internet, buscando informações e, principalmente, conteúdo interativo. Nesse sentido, é decepcionante para o consumidor procurar informações sobre um produto ou serviço e não encontrar. Essa busca vã traz o sentimento de que a marca não existe, fato que permite à concorrência conquistar esse público que a marca acabou de perder. Além disso, incentiva-se a presença da marca Energy em eventos e casas noturnas do Rio Grande do Sul: lugares em que o produto precisa estar devido ao seu posicionamento, que se 
relaciona a festas e eventos com muita música, luzes e energia a noite toda.

Ademais, incentiva-se a marca a patrocinar grandes shows e eventos em âmbito nacional e regional, assim como a realizar samplings. No ano de 2015, pode-se verificar que isso já vem acontecendo, pois o Energy patrocinou o Lollapalooza e o Tomorrowland e realizou samplings periodicamente, sobretudo nos ambientes de autosserviço, como supermercados e hipermercados.

Seria desejável, também, elevar a disponibilidade do produto nos PDV. Por meio de conversas informais na Empresa $\mathrm{X}$, verificou-se que há pouca saída do produto nos PDV, motivo pelo qual estes evitam comprá-lo. É necessário, assim, criar estratégias que incentivem o PDV a comprar Energy; dessa forma, haverá mais produtos nas prateleiras dos supermercados e em bares e festas. Muitas pessoas relatam não encontrar Energy nem se lembram de vê-lo nos PDV, situação que precisa ser revertida.

No presente estudo, embora sugestões sejam expostas, é necessário que a cultura de interação se perpetue na Empresa X. O Energy precisa investir em ações de marketing que estejam presentes no cotidiano de seu público-alvo, pois, ao ser visto, despertará curiosidade e, possivelmente, um grande relacionamento com o público.

\subsection{Planos de ação}

Após realizar as análises e reunir as informações adquiridas na Empresa $X$, foi possível estabelecer alguns planos de ação para fortalecer o Energy e, consequentemente, impulsionar seu market share. Segundo Silva e Tincani (2013, p. 152),

O Marketing de Experiências também pode ser aplicado em eventos, como festivais musicais e shows, onde o consumidor tende a estar mais propício a receber informações e estímulos que provoquem experiências diferentes, desde que essas estejam no mesmo clima do evento em que estão sendo utilizadas, e essa é uma proposta que vem sendo muito buscada pelas empresas a fim de complementar a comunicação tradicional e aumentar a interação com o público-alvo.

Nesse sentido, ao utilizar as estratégias de marketing de experiência e neuromarketing, buscou-se focar na promoção. Conforme as estratégias de gestão da experiência do cliente, primeiramente, analisou-se o perfil do público-alvo. Em seguida, verificou-se o que o consumidor espera, para, então, proceder a uma revisão do posicionamento que está sendo trabalhado pela marca. Após, a experiência foi projetada, alinhando o que o público gosta ao que a empresa quer entregar a ele, incluindo nesse rol o que é desejável ao cliente e os elementos de ver e sentir. A seguir, encontram-se duas ações planejadas: Energy Experience e Momento Energy.

\subsubsection{Energy Experience}

Partindo do desejo de proporcionar ao público uma experiência diferente na companhia do Energy, surgiu o Energy Experience. A ação de marketing acontecerá em casas noturnas e eventos de Porto Alegre e Santa Maria. A ação possuirá um gazebo (ou container) na cor branca ou preta, na entrada ou no interior de algumas casas noturnas e eventos da cidade. Os frequentadores (após planejamento com os proprietários do estabelecimento) entrarão no local através do gazebo.

Dentro desse gazebo estará acontecendo uma pocket night, conforme ilustrado nas Figuras 2, 3, 4, 5 e 6, que se caracteriza pelos seguintes atributos: pista de LED, na cor verde neon e com uma textura quadriculada, com a logomarca do energético gravada em diagonal; um minibar com balcão e duas cadeiras altas em prata e preto, duas cadeiras com design moderno, um sofá, um barman e duas 
promotoras; DJ e equipamentos; duas telas LED com vídeos de grandes shows e baladas; dois painéis com câmera acoplada para selfies a partir do toque (da palma da mão) na tela touchscreen; dois a três dados grandes junto com as promotoras $(60 \mathrm{~cm} \times 60 \mathrm{~cm} \times 60 \mathrm{~cm})$, apresentando as faces "Energy", "Voucher", "Jogue novamente" e "Não foi dessa vez"; quatro frigobares de Energy, em prata, com luzes verdes; chão em preto; paredes em branco e preto; luzes e LEDs em verde.

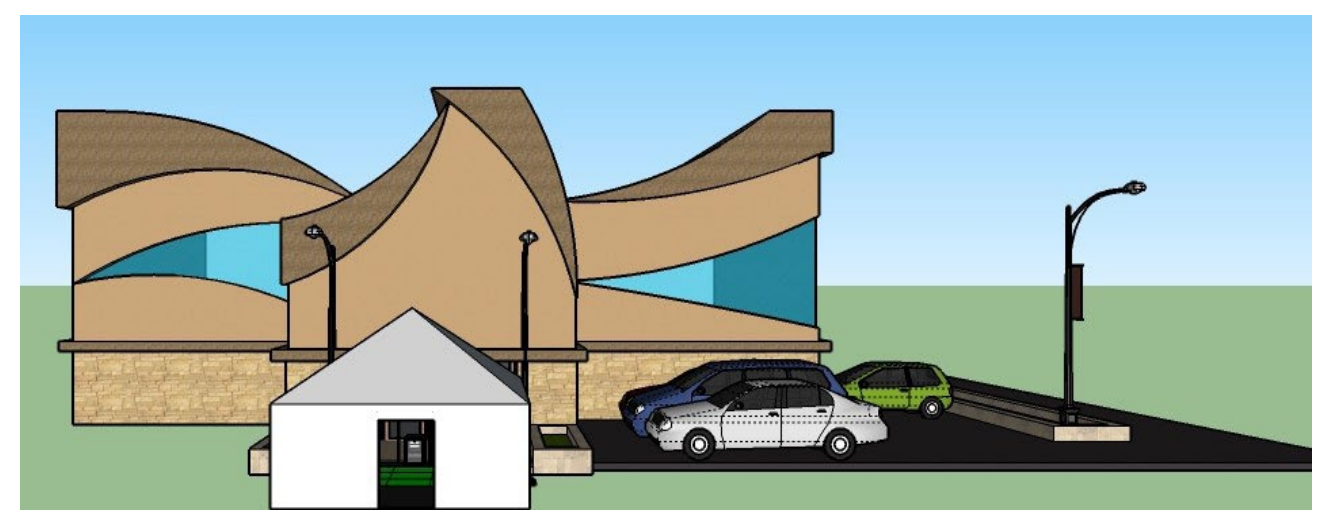

Figura 2 - Projeto ilustrativo da estrutura - exterior e entrada da casa noturna/evento. Fonte: elaborada pelos autores.

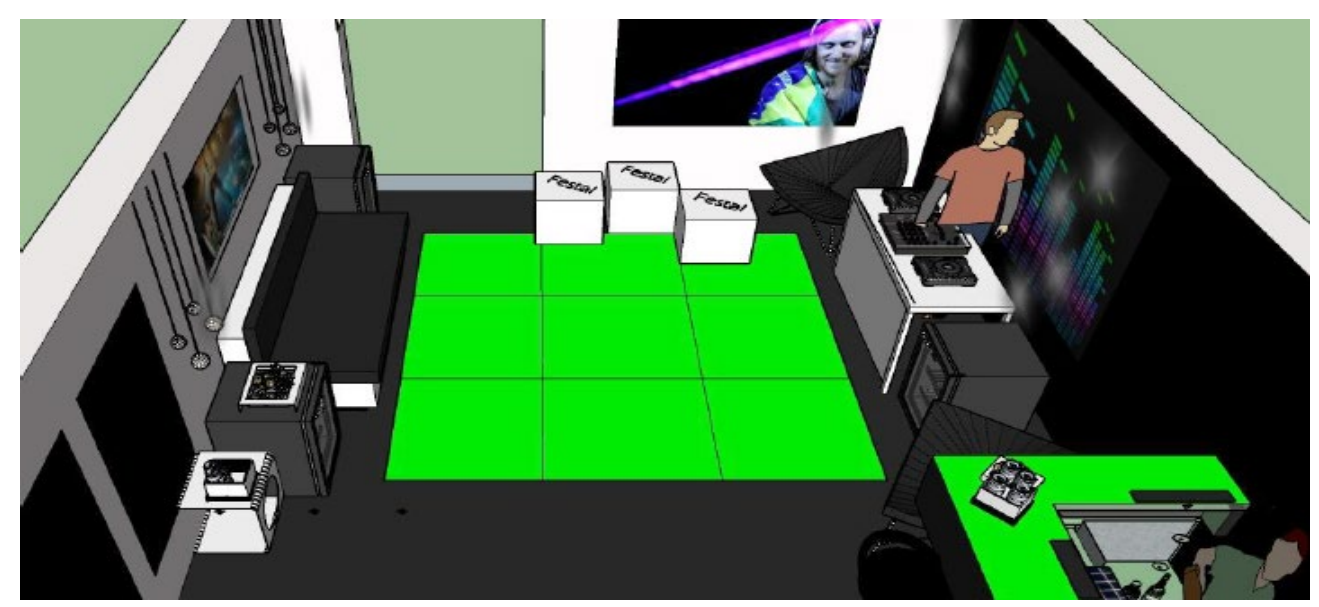

Figura 3 - Projeto ilustrativo da estrutura - interior. Fonte: elaborada pelos autores.

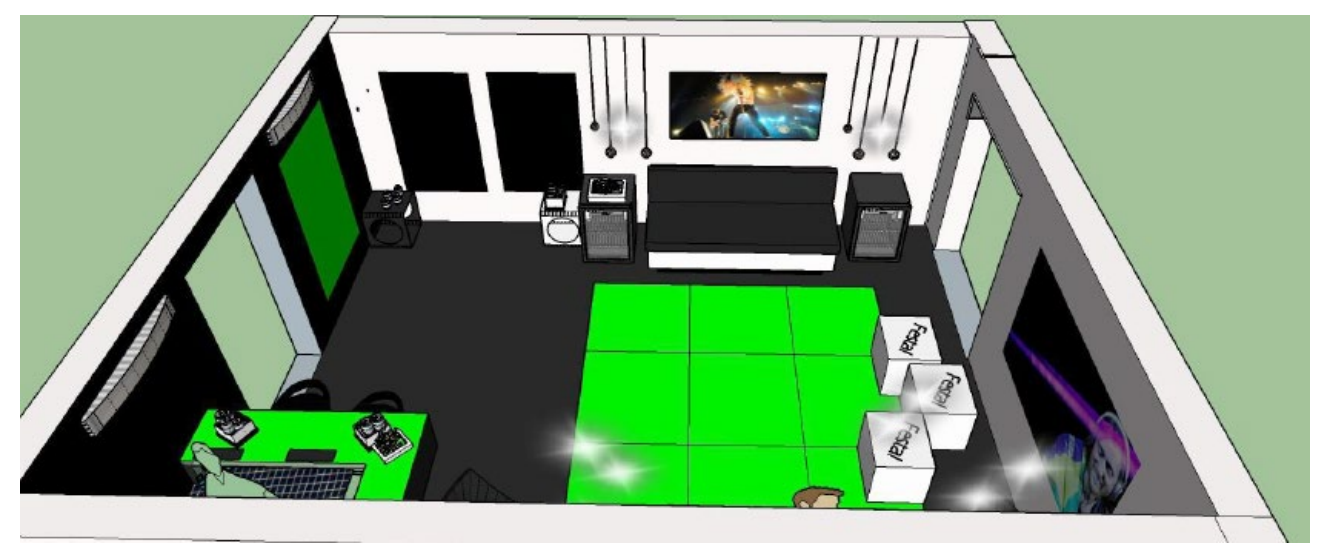

Figura 4 - Projeto ilustrativo da estrutura - interior/lado esquerdo.

Fonte: elaborada pelos autores. 


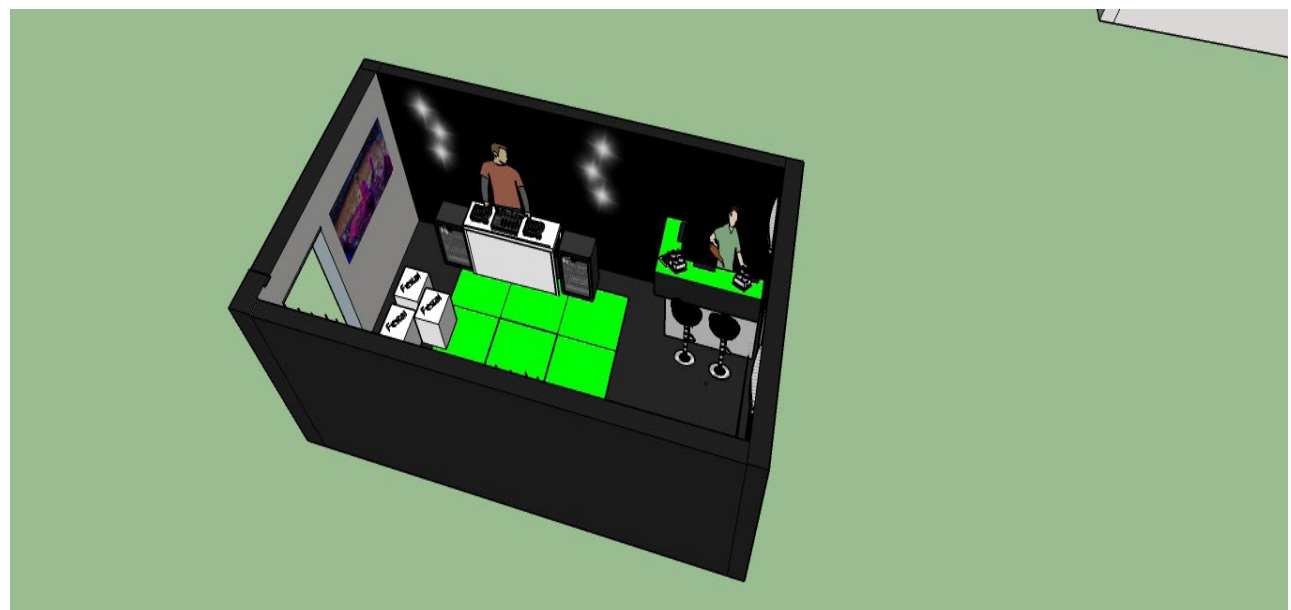

Figura 5 - Projeto ilustrativo da estrutura - vista de cima do container. Fonte: elaborada pelos autores.

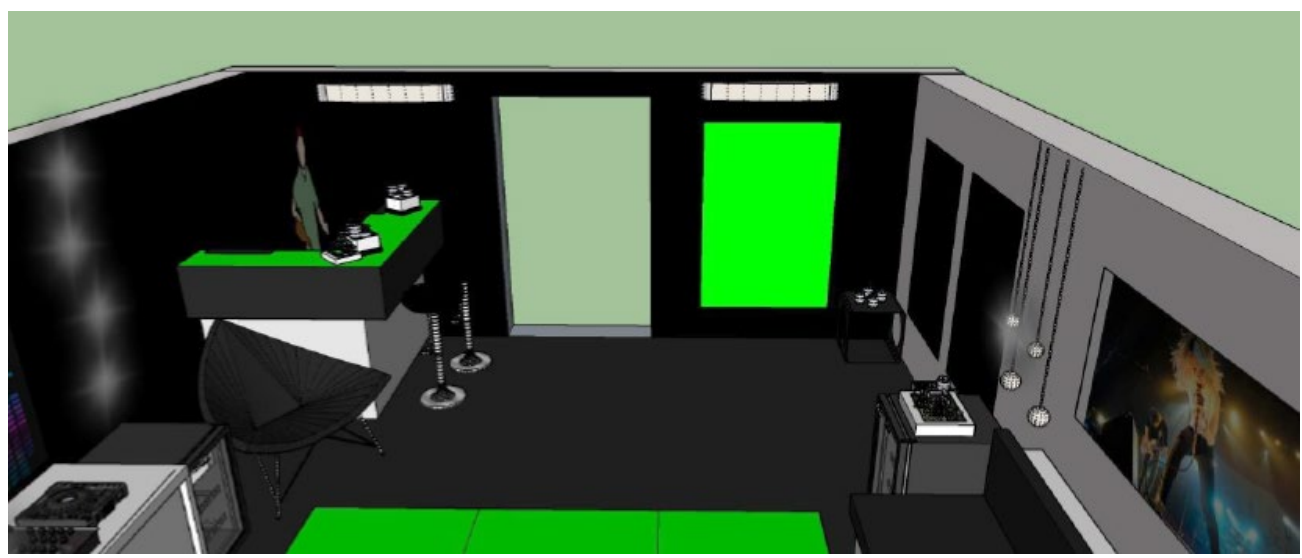

Figura 6 - Projeto ilustrativo da estrutura - interior. Fonte: elaborada pelos autores.

Ao entrar no gazebo, a pessoa receberá uma pulseira neon personalizada e uma unidade de Energy para beber, com a opção de levar apenas a lata ou ser servido em um copo personalizado. Um barman estará em um pequeno balcão de bar à direita, servindo as pessoas com o auxílio de uma promotora. À esquerda, a pessoa encontrará dois painéis pretos em que poderá tirar selfies com o auxílio de uma câmera frontal acoplada e acionada pelo toque da palma da mão na tela.

No meio do ambiente, estará uma pista em LED verde, quadrada e com textura quadriculada; e na lateral, haverá um DJ que irá interagir com o público. Luzes, LEDs e painéis com a imagem do energético estarão no ambiente, assim como duas telas LED's com vídeos de bandas, shows e baladas sendo exibidos durante as horas de funcionamento da ação.

A ferramenta $5 \mathrm{~W} 2 \mathrm{H}$, sigla formada por sete iniciais de perguntas em inglês - What? (O quê), Why? (Por quê?), Who? (Quem?), When? (Quando?), Where? (Onde?), How? (Como?) e How much? (Quanto?) -, é utilizada no planejamento de diversas organizações, tendo como objetivo deixar claras todas as etapas da ação a ser realizada. A seguir, no Quadro 4, encontra-se a 5W2H da Energy Experience. 


\begin{tabular}{|c|c|}
\hline \multicolumn{2}{|r|}{ Energy Experience } \\
\hline What? & Circuito de ações de marketing de experiência. \\
\hline Why? & Divulgar o Energy e promover interação da marca com o público-alvo. \\
\hline Who? & $\begin{array}{l}\text { Agência de publicidade contratada e equipe do setor de energéticos da com- } \\
\text { panhia. }\end{array}$ \\
\hline When? & $\begin{array}{c}\text { Segundo semestre de } 2015, \text { com datas a serem acertadas com os estabeleci- } \\
\text { mentos. }\end{array}$ \\
\hline Where? & $\begin{array}{l}\text { Casas noturnas e eventos de Porto Alegre e Santa Maria, com probabilidade } \\
\text { de expansão para outras cidades do estado. }\end{array}$ \\
\hline How? & $\begin{array}{l}\text { A ação possuirá um gazebo (ou container) na cor branca ou preta, na entrada } \\
\text { de algumas casas noturnas e eventos. Os frequentadores entrarão no local } \\
\text { através do gazebo, onde viverão uma pocket night. Quatro dos cinco sentidos } \\
\text { serão trabalhados na experiência: tato, paladar, audição e visão. }\end{array}$ \\
\hline How Much? & $\begin{array}{c}\text { O orçamento está em processo de planejamento junto à agência - a empresa } \\
\text { dispõe de } 100 \text { mil reais para as ações. }\end{array}$ \\
\hline
\end{tabular}

Quadro 4-5W2H da Energy Experience.

Fonte: elaborado pelos autores.

O sentido visão será estimulado pelas luzes, pelos vídeos e pelas cores verde, preto e branco, que estarão em evidência no ambiente. Essas cores estão presentes na comunicação visual do Energy, e o estímulo no ambiente tende a fazer com que os frequentadores associem as cores ao produto. Em seguida, o sentido da audição será bastante estimulado por meio das músicas que estarão tocando no ambiente: a playlist do DJ será planejada para que não faltem músicas eletrônicas, electro house e, principalmente, músicas que estão fazendo sucesso no momento.

O tato será estimulado pelo toque gelado da lata ou copo em que será servido o energético, além do toque na tela touchscreen para que a foto seja acionada. Após registrar a foto, a pessoa poderá compartilhá-la em alguma rede social ou enviá-la para o seu e-mail pessoal. 0 paladar, quarto sentido utilizado nas estratégias, será estimulado pela experimentação do energético - a característica indispensável para o contato com o produto é que ele esteja em uma temperatura muito baixa.

Do meio do ambiente para o final, duas promotoras estarão com dados nas mãos. Esses dados possuem as seguintes faces: "Energy", "Festa", "Jogue novamente" e "Não foi dessa vez". Individualmente, as pessoas terão a oportunidade de jogar o dado: se cair a face "Energy", a pessoa ganhará mais uma lata de energético; se cair a face "Festa", ela ganhará um voucher para entrar na festa ou no evento em que a ação está acontecendo; se cair a face "Jogue novamente", ela poderá jogar o dado mais uma vez; e se cair a face "Não foi dessa vez", a pessoa não ganhará nada.

\subsubsection{Momento Energy}

Para as casas noturnas que não possuem área externa e, portanto, não podem realizar a ação do Energy Experience, há a ação do Momento Energy. Com um lounge interno, a Energy estará presente durante toda a noite, no interior da casa noturna, com baldes de gelo contendo latas de $250 \mathrm{ml}$ de Energy, copos em verde-neon, canudinhos pretos e pulseiras verde-neon que serão entregues na entrada junto com a comanda.

Durante a noite, ocorrerão dois momentos Energy: a música vai parar por aproximadamente três segundos; após esse intervalo de tempo, luzes verdes e LEDs serão ligadas, a música eletrônica começará novamente; e haverá rodadas duplas de Energy (Paga 1, Leva 2). O estabelecimento pode dispor de promotoras caminhando entre o público, com bandejas contendo copos cheios de Energy, e realizando a entrega gratuita do produto para as pessoas. 


\section{CONSIDERAÇÕES FINAIS}

As empresas que possuem uma visão de longo prazo já estão percebendo quão valiosas são as ações que buscam estreitar o relacionamento com o cliente e proporcionam a ele grandes experiências. O cliente precisa sentir a marca e relembrar dos pontos de contato com a empresa; para isso, torna-se necessário proporcionar a ele experiências novas e envolventes, diferente de tudo o que já viu antes.

Nesse contexto, o presente estudo buscou estratégias para sanar as dificuldades de visibilidade de marca que o Energy enfrenta no sul do país. A pouca visibilidade que o energético possui, diante dos seus concorrentes, é um fator que pode estar impactando o seu market share. Tendo em vista que a decisão de compra e o desejo de ser fiel a uma marca são influenciados pelas emoções (KOTLER, 2010), o intuito consistiu em planejar ações para fortalecer a marca e impulsionar o market share do Energy por meio de estratégias de marketing de experiência. Nesse sentido, o planejamento de uma pocket night na frente de casas noturnas e grandes eventos no Rio Grande do Sul quer envolver o público-alvo no universo da marca, proporcionar a ele a fusão do dia com a noite e, principalmente, fazer com que o Energy o acompanhe nas festas e em seus eventos preferidos.

Como descrito no presente estudo, acredita-se que, com um planejamento de ações de marketing frequentes, é possível aumentar o share de mercado de uma marca em médio e longo prazo. Por meio de um crescimento no volume de vendas, a porcentagem de share tende a aumentar, fazendo com que o Energy se aproxime dos líderes do segmento de energéticos. Vale ressaltar que, ao aumentar a visibilidade da marca, a procura do energético nos PDV crescerá, pois o público tende a ser movido pela curiosidade de conhecer o produto que visualizou em alguma ação.

Nesse sentido, espera-se fazer com que o Energy seja lembrado e reconhecido pelo seu público-alvo em sua rotina, sendo essa uma das maiores deficiências do produto no momento. Propõe-se, assim, à organização a realização dos circuitos de ação de marketing de experiência descritos no presente estudo, assim como outras ações de marketing e intervenções que busquem a interação com o público-alvo do Energy. A seguir, no Quadro 5, são apresentadas as principais ações de marketing sugeridas para a Empresa $X$.

\footnotetext{
Ações de marketing sugeridas

Aumentar visibilidade nas mídias (YouTube, Multishow, MTV etc.)

Aumentar presença em eventos

Aumentar disponibilidade do produto no PDV

Intensificar ações de sampling

Elevar patrocínios de shows e eventos

Reduzir vínculo com a bebida Soft

Criar estratégias que incentivem o PDV a comprar Energy

Criar intervenções urbanas

Promover Energy Experience

Propiciar Momento Energy

Quadro 5 - Ações de marketing sugeridas

Fonte: elaborado pelos autores.
}

Vale ressaltar, por fim, que, as estratégias desenvolvidas neste trabalho buscam, por meio da interação, fortalecer o relacionamento do consumidor com o energético. Espera-se, assim, fazer com que o Energy seja lembrado e reconhecido pelo seu público-alvo. 


\section{REFERÊNCIAS}

ABREU, Nelsio Rodrigues de; BALDANZA, Renata Francisco; GONDIM, Sônia M. Guedes. Os grupos focais on-line: das reflexões conceituais à aplicação em ambiente virtual. JISTEM - Journal of Information Systems and Technology Management, v. 6, n. 1, p. 5-24, 2009.

\section{AMERICAN MARKETING ASSOCIATION.} Definition of Marketing. 2013. Disponível em: $<$ www.ama.org/AboutAMA/Pages/Definitionof-Marketing.aspx>. Acesso em: 10 jun. 2015.

BIZZOTTO, Carlos Eduardo Negrão. Plano de negócios para empreendimentos inovadores. São Paulo: Atlas, 2008

BLOOM, Paul; KOTLER, Philip. Strategies for High Market-Share Companies. Disponível em: <www.hbr.org/1975/11/strategies-forhigh-market-share-companies>. Acesso em: 30 maio 2015.

CAIXETA, C; JANSEN, M. Marketing de relacionamento. São Paulo: Independentes, 2011.

CARVALHO, Ricardo Monteiro de et al. A obtenção de uma nova curva de valor através do modelo das quatro ações de Kim e Mauborgne. In: CONGRESSO NACIONAL DE EXCELÊNCIA EM GESTÃO, 5., 2009, Niterói. Anais... Niterói: CNEG, 2009. Disponível em: <http:// www.excelenciaemgestao.org/Portals/2/ documents/cneg5/anais/T8_0192_0661.pdf>. Acesso em: 15 maio 2015.

ENERGY. Marca. Disponível em: <http://www. energy.com.br/marca>. Acesso em: 08 abr. 2015.

FERNANDES, Natalia. Marketing de relacionamento e suas aplicações. 2013. Disponível em:<www.businessreviewbrasil. com.br/marketing/1138/Marketing-derelacionamento-e suas-aplicaccedilotildees $>$.
Acesso em: 14 abr. 2015.

GUIA DO MARKETING. 0 que é participação de mercado (market share)? 2013. Disponível em: <guiadomarketing.powerminas.com/o-quee-participacao-de-mercado-market-share/>. Acesso em: 15 maio 2015.

KIM, Chan W.; MAUBORGNE, Renée. Blue Ocean Strategy: How to Create Uncontested Market Space and Make the Competition Irrelevant. Brighton: Harvard Business School Publishing Corporation, 2005.

KOTLER, Philip. Administração de marketing: a edição do novo milênio. São Paulo: Atlas, 1998.

KOTLER, P; KARTAJAYA, H; SETIAWAN, I. Marketing 3.0: as forças que estão definindo o novo marketing centrado no ser humano. Rio de Janeiro: Elsevier, 2010.

LENZI, F; KIESEL, M; ZUCCO, F. Ação empreendedora: como desenvolver $e$ administrar o seu negócio com excelência. São Paulo: Gente, 2010.

LINDSTROM, Martin. Brand Sense: a marca multissensorial. Prefácio de Philip Kotler. Porto Alegre: Bookman, 2007.

LUÍS, Diego. Era marketing de experiência. 2014. Disponível em: <www.plugcitarios. com / 2014 / 02 / e ra-marketing-deexperiencia/> Acesso em: 15 maio 2015.

MALHOTRA, Naresh. Introdução à pesquisa de marketing. São Paulo: Prentice Hall, 2005.

MARKET, Design; Marketing de experiência. Disponível em: <www.marketdesign.com.br/ marketing-de-experiencia.php $>$. Acesso em: 13 abr. 2015.

MELLO, Fábio Bandeira. Você já ouviu falar em marketing sensorial? 2010. Disponível e $m:<w w w$.administradores.com.br/ entrevistas/marketing/voce-ja-ouviu-falar-emmarketing-sensorial/8/> Acesso em: 22 maio 2015 
MORGAN, David. Focus group as qualitative research. Qualitative Research Methods Series. London: Sage Publications, 1997.

QUEIRÓS, Felisbela F. T. Galante de et al. Bebida energética Beta. Matosinhos: Ipam, 2010.

RABELO, Claudio. Curso de marketing contemporâneo - aula 01 . 17'17'. Disponível em: < www.youtube.com/ watch?v=vXMovqd0I3w>. Acesso em: $28 \mathrm{abr}$. 2015.

RABELO, Claudio. Curso de marketing contemporâneo - aula 02 . 22'14". Disponível em: < www.youtube.com/ watch?v=rvM5MXFzLFs $>$. Acesso em: 17 maio 2015.

ROCHA, Sergio Ricardo. Marketing de experiência para entrar na mente dos consumidores. 2013. Disponível em: <www. sergioricardorocha.com.br/marketing-deexperiencia-para-entrar-na-mente-dosconsumidores/>. Acesso em: 15 maio 2015.

SANTINI, Fernando R.; LUDOVICO, Nelson. Gestão de Marketing: o plano de marketing como orientador das decisões. São Paulo: Saraiva, 2013.

SCHMITT, Bernd. Gestão da experiência do cliente: uma revolução no relacionamento com os consumidores. Porto Alegre: Bookman, 2004.

SILVA, Mikeli Aparecida da; TINCANI, Daniela Pereira. Características e componentes do marketing de experiências: análise das ações realizadas pelo Itaú Unibanco no rock in rio 2011. Revista Científica Eletrônica UNISEB, Ribeirão Preto, v. 1, n. 2, p. 147-161, ago./dez. 2013.

VANUCCl, Gustavo. Como aumentar o market share de forma sustentável. 2009. Disponível em:<www.administradores.com.br/artigos/ negocios/como-aumentar-o-market-share-deforma-sustentavel/33162/>. Acesso em: 20 maio 2015.
VEIGA, Luciana; GONDIM, Sônia Maria Guedes. A utilização de métodos qualitativos na ciência política e no marketing político. Opinião Pública, Campinas, v. 2, n. 1, p. 1-20. 2001.

WAGNER, Fernanda Bastos. A elaboração de um plano de negócios para a bebida energética denominada Beta. 2011. 57 f. Monografia (Especialização em Marketing) - Universidade Candido Mendes, Rio de Janeiro, 2011. 